\title{
Correlation the between the regulation of miRNA-1 in c-Met-induced EMT and cervical cancer progression
}

\author{
YUN CHENG ${ }^{1}$, MINLIANG YANG ${ }^{2}$ and JINGXIAN PENG ${ }^{3}$ \\ ${ }^{1}$ Department of Histology and Embryology, School of Preclinical and Forensic Medicine, Baotou Medical College, Baotou, \\ Inner Mongolia 014000; ${ }^{2}$ Medical Ultrasound Center, Northwest Women's and Children's Hospital, Xian, Shanxi 710000; \\ ${ }^{3}$ Microbiology Laboratory, Baotou Center for Disease Control and Prevention, Baotou, Inner Mongolia 014000, P.R. China
}

Received March 6, 2018; Accepted October 19, 2018

DOI: $10.3892 /$ ol.2019.9971

\begin{abstract}
Cervical cancer is a common malignant tumor of the female reproductive system. Despite advances in cervical cancer therapy, tumor recurrence and metastasis remain the leading cause of mortality for patients with cervical cancer. Therefore, the investigation of tumorigenesis and progression, and the search for novel therapeutic targets, has been the primary focus in cervical cancer research. The aims of the present study were: i) To analyze the alterations in c-Met, E-cadherin and microRNA (miRNA)-1 expression levels in cervical cancer tissues; ii) to assess the correlation between the above genes and the pathological characteristics of the cancer tissues; and iii) to examine the potential mechanism through which miRNA-1 may regulate c-Met-induced epithelial-mesenchymal transition to promote the development of cervical cancer. In cervical cancer tissues, c-Met was more highly expressed, while E-cadherin exhibited lower expression levels compared with the adjacent tissues. The 24-month follow-up reported that a lower c-Met expression level was correlated with higher E-cadherin expression levels and a longer survival rate. The miRNA-1 expression level in cancer tissues was $0.41 \pm 0.07$ times lower compared with the adjacent tissues $(\mathrm{P}<0.01)$. A low miRNA expression level was correlated with a low survival rate of patients. In vitro, miRNA-1 inhibited the proliferation and migration of cervical cancer cell lines by downregulating c-Met mRNA. When miRNA-1 expression was downregulated in cervical cancer tissues, the inhibition of c-Met expression was reversed. The upregulation of c-Met expression levels was able to inhibit E-cadherin expression, which triggered the proliferation, migration and infiltration of cancer cells, and thus reduced patient survival rates.
\end{abstract}

Correspondence to: Dr Jingxian Peng, Microbiology Laboratory, Baotou Center for Disease Control and Prevention, 44 Linbei Road, Qingshan, Baotou, Inner Mongolia 014000, P.R. China E-mail: pengjingxian1368@163.com

Key words: microRNA-1, c-Met, E-cadherin, cervical cancer, survival analysis

\section{Introduction}

Cervical cancer, with an incidence rate second only to that of breast cancer, is a common malignant tumor of the female reproductive system. Upon diagnosis, the majority of patients are already in the middle to advanced stages of disease, and incidence rates among young patients are increasing annually (1) Therefore, the investigation of tumorigenesis and progression, and the search for novel therapeutic targets, has been the primary focus in cervical cancer research $(2,3)$. Due to recent advances in therapy, including surgery, radiotherapy and chemotherapy, and the clinical application of antitumor drugs, therapeutic effects have been promoted, and patient survival rates and quality of life have been improved. However, tumor recurrence and metastasis remain the leading cause of mortality for patients with cervical cancer.

MicroRNAs (miRNAs) are a group of single-stranded non-coding RNA molecules containing 19-25 nucleotides, which exist widely in eukaryotes. miRNAs bind to the 3 'translated region (UTR) of their target mRNA via complementary base pairing, which regulates target gene expression by degrading the target mRNA or inhibiting translation. miRNAs are involved in the activation of a variety of biological events and signal transduction pathways, and serve a mediating role in cell proliferation, differentiation and malignant transformation. Their biological functions extend throughout the development and growth of living organisms $(4,5)$. Endogenous miRNAs exert specific biological effects in different physiological and pathological situations (6). Studies have reported that miRNAs are correlated with tumorigenesis, progression, invasion and metastasis. Certain miRNAs are proto-oncogenes that promote tumor cell proliferation and migration; others are cancer suppressor genes that induce tumor cell apoptosis, and inhibit tumor cell invasion and metastasis (7). It is predicted that miRNAs are able to regulate the activation of $\sim 50 \%$ of protein-coding genes in mammals; the metabolism and biological functions of miRNAs may also be tightly regulated (8).

miRNA-1 has attracted extensive attention as a cancer suppressor gene. Its expression is downregulated in a variety of tumors, including head and neck squamous carcinoma (9) and thyroid cancer (10). Its expression level is lower in tumor tissues compared with adjacent tissues. Alterations in miRNA-1 expression levels are associated with the occurrence and development 
of cervical cancer, and miRNA-1 primarily acts on the 3' UTR and 5' UTR of c-Met mRNA to guide its mRNA degradation or prevent its translation (11). Epithelial-mesenchymal transition (EMT) is a principal factor affecting the migration, invasion and metastasis of tumors, in which tumor cells inhibit the expression of adhesion molecules in epithelial cells, reduce the intercellular adhesion, degrade the matrix around the tumor cells and detach the cells from the epithelial tissue, followed by invasion and distant metastasis. c-Met has been confirmed to be involved in EMT and to be closely associated with tumorigenesis and progression (12). The present study examined the association between the regulation of miRNA-1 in c-Met-induced EMT and cervical cancer tumorigenesis and progression, by analyzing the alterations in the expression levels of c-Met, E-cadherin and miRNA-1 in cervical cancer tissues, aiming to provide a novel strategy for the clinical diagnosis and treatment of early-stage cervical cancer.

\section{Materials and methods}

Sample collection. Tumor tissues and adjacent tissues $(>5 \mathrm{~cm}$ from the tumor tissue edge) were collected from 50 patients with cervical cancer admitted to The People's Hospital of Inner Mongolia Autonomous Region (Inner Mongolia) between March 2015 and March 2017. Tissue samples were transported in liquid nitrogen and stored at $-80^{\circ} \mathrm{C}$. Based on pathological examinations, all 50 patients were confirmed as having cervical cancer (including 25 squamous cancer cases, 20 adenocarcinoma cases and five cases of other types).

Clinical information. None of the 50 patients (aged 35-71 years; mean age $56.3 \pm 8.7$ years) underwent preoperative radiotherapy or chemotherapy. According to the Federation of Gynecology and Obstetrics (FIGO) clinical staging standards (13), 29 cases were in stage Ib-IIa, 13 cases in stage IIb-IIIa and eight cases in stage $\geq$ IIIlb. The Ethics Committee of The People's Hospital of Inner Mongolia Autonomous Region approved this study. Informed consent was obtained from all the recruited patients and their relatives.

Cell culture and transfection. The human cervical cancer cell line HeLa [human papillomavirus (HPV) $18^{+}$] cultured with Dulbecco's modified Eagle's medium and $10 \%$ fetal bovine serum (Gibco; Thermo Fisher Scientific, Inc., Waltham, MA, USA) at $37^{\circ} \mathrm{C}$ in a $5 \% \mathrm{CO}_{2}$ incubator. HeLa cells at a density of $2 \times 10^{6} / \mathrm{ml}$ were seeded in 96 -well plates with $10^{4}-10^{5}$ cells/well, Each well contains $1 \mathrm{ml}$ of HeLa cells with $10 \%$ fetal bovine serum in a $5 \% \mathrm{CO}_{2}$ incubator culture at $37^{\circ} \mathrm{C}$. The miRNA-1 was transfected including negative control (miRNA NC; Guangzhou RiboBio Co., Ltd., China) and mimic (Guangzhou RiboBio Co., Ltd., China) using Lipofectamine ${ }^{\circledR} 2000$ reagent (Invitrogen; Thermo Fisher Scientific, Inc.). The following sequences were used: miRNA-1 mimic agomir sense 5'-UGG AAUGUAAAGAAGUAUGUAU-3', antisense 5'-ACCUGC ACGAACAGCACUUUGUU-3'. The negative control for the agomir was sense 5'-UUCUUCGAACGUGUCACG UTT-3', antisense ACGUGACACGUUCGGAGAATT-3'. At 1 day following seeding. Subsequent to transfection, the final concentration of miRNA mimics was $50 \mathrm{nM}$. Cells were cultured for $24-48 \mathrm{~h}$ prior to experiments.
Reverse transcription-quantitative polymerase chain reaction $(R T-q P C R)$. The cervical tissue samples $(50 \mathrm{mg}$; stored at $-80^{\circ} \mathrm{C}$ ) or HeLa cells were ground with a small quantity of liquid nitrogen and $1 \mathrm{ml}$ TRIzol ${ }^{\circledR}$ (Thermo Fisher Scientific, Inc.) in a mortar. Following transfer to an RNAse-free Eppendorf tube, the suspension was centrifuged for $10 \mathrm{~min}$ $\left(1,000 \times \mathrm{g}, 4^{\circ} \mathrm{C}\right)$. The supernatant obtained was transferred to a new Eppendorf tube, to which chloroform was added, and shaken for $15 \mathrm{sec}$, incubated at room temperature for $5 \mathrm{~min}$ and centrifuged for $10 \mathrm{~min}\left(1,000 \mathrm{x} \mathrm{g}, 4^{\circ} \mathrm{C}\right)$. The supernatant was transferred to another Eppendorf tube, to which the same volume of isopropanol was added, thoroughly mixed, incubated at room temperature for $10 \mathrm{~min}$ and centrifuged for $10 \min \left(1,000 \times \mathrm{g}, 4^{\circ} \mathrm{C}\right)$. Following removal of the supernatant, the mixture was combined with $1 \mathrm{ml}$ ethanol (75\%), gently blown and washed using a pipette tip with $1 \mathrm{ml}$ RNA free enzyme (Thermo Fisher Scientific, Inc.), and centrifuged for $5 \min \left(1,000 \times \mathrm{g}, 4^{\circ} \mathrm{C}\right)$. Subsequently, the ethanol was removed; the mixture was incubated at room temperature or dried at $60^{\circ} \mathrm{C}$, and combined with diethyl pyrocarbonate to dissolve the precipitate. Upon the complete dissolution of the RNA precipitate, the mixture was stored in the freezer at $-80^{\circ} \mathrm{C}$. Formaldehyde-modified agarose gel electrophoresis $(1 \%)$ was performed in order to confirm the completeness of the RNAs. The RNA concentration and purity was measured using a UV spectrophotometer. If the ratio of absorbance at $260 \mathrm{~nm}$ (A260)/A280 was between 1.8 and 2.0, the sample qualified for reverse transcription. The RT reaction was conducted using an miRNA RT kit (Takara Bio, Inc., Otsu, Japan), with a $20 \mu \mathrm{l}$ reaction system, following the manufacturer's instructions. PCR amplification was conducted using SYBR Premix Ex Taq $^{\mathrm{TM}}$ II (Takara Biotechnology Co., Ltd., Dalian, China) with a 20- $\mu 1$ reaction system under the conditions of $95^{\circ} \mathrm{C}$ for $30 \mathrm{sec}$, $95^{\circ} \mathrm{C}$ for $3 \mathrm{sec}$ and $60^{\circ} \mathrm{C}$ for $30 \mathrm{sec}$ for 40 cycles, following the manufacturer's instructions. The primer sequences used were as follows: miRNA-1 forward (F)5'-TGTAGTTTCGGAGTT AGTGTCGCGC-3', reverse (R)5'-CCTACGATCGAAAAC GACGCGAACG-3'; U6 reference gene F5'-GTTTTGTAG TTTTTGGAGTTAGTGTTGTGT-3', R5'-CTCAACCTACAA TCAAAAACAACACAAACA-3'.

Based on the $\mathrm{Cq}$ value, the $2^{-\Delta \Delta \mathrm{Cq}}$ method was used to calculate the relative expression level of miRNA-1, normalized to the internal U6 reference gene.

Immunohistochemical analysis. The cervical cancer tissue and normal adjacent tissue was fixed in $4 \%$ periodate-lysine-paraformaldehyde $\left(48 \mathrm{~h}, 4^{\circ} \mathrm{C}\right)$ and routinely dehydrated, permeabilized and embedded in paraffin using a Leica embedding machine (Leica Microsystems, Inc., Buffalo Grove, IL, USA). Using an RM2016 slicing machine (Leica, Wetzlar, Germany), the paraffin blocks were sliced into 5- $\mu \mathrm{m}$ serial paraffin sections, which were placed in an oven $\left(65^{\circ} \mathrm{C}\right)$ overnight. Hydrated tissue sections were treated with $3 \%$ hydrogen peroxide solution to block endogenous peroxidase; the sections were subsequently acid-fixed using a pre-configured citrate buffer and the sections were placed in liquid using a microwave heating method. Following repair, blocking was performed with $1 \%$ bovine serum albumin (Thermo Fisher Scientific, Inc.) at room temperature for $30 \mathrm{~min}$. Primary antibodies were incubated overnight at $4^{\circ} \mathrm{C}$ (rabbit anti-c-Met, ab51067, 1:200 
dilution; rabbit anti-E-cadherin, ab76319, 1:200 dilution; both Abcam, Cambridge, UK). Horseradish peroxidase-labeled goat anti-rabbit secondary antibody (ab150077, 1:200, Abcam) was added to the tissue sections and incubated for $1 \mathrm{~h}$ at room temperature. Following 3,3'-diaminobenzidine staining at room temperature for $10 \mathrm{~min}$, hematoxylin staining was performed at room temperature for $1 \mathrm{~min}$, followed by dehydration and neutral resin packing. Positive images were observed with a vertical microscope at x400 magnification and counted.

Dual luciferase reporter gene assay. A PsiCHECK-2 plasmid system (Promega Corporation, Madison, WI, USA) was used to analyze the combination of miRNA-1 and c-Met. The plasmid contained two different luciferase genes: One gene was regulated by the combination of the 3'UTR insert and the transfected miRNA, while the other gene was not regulated and acted as a control. The predicted sequence was amplified by RT amplification from the HeLa cell total RNA and cloned to the vector, namely the wild-type plasmid. The site was mutated and cloned via the overlapping elongation method to construct the mutant plasmid. The plasmids were purchased from Promega Corporation and were transfected with the siPORTNeoFX Transfection Agent (Ambion, Thermo Fisher Scientific, Inc.) into HeLa cells, with the plasmid transfection with miRNA-negative control (NC) mimic acting as the control group. A total of $24-48 \mathrm{~h}$ post-transfection, luciferase activity was detected using Dual-Luciferase ${ }^{\circledR}$ Reporter Assay System reagent (Promega Corporation) and the Promega Dual-Luciferase ${ }^{\circledR}$ Report 96-well detector (Promega Corporation). The luciferase activity was determined via comparison with Renilla luciferase activity when the cells had been lysed with a passive lysis buffer, using the Dual-Luciferase Reporter assay system (Promega Corporation).

Western blotting. Cellular proteins were extracted using radioimmunoprecipitation assay buffer (P0013B, Beyotime Institute of Biotechnology, Haimen, China) was used to extract total protein from the cells. Protein concentration was determined using a bicinchoninic acid assay. The proteins $(50 \mu \mathrm{g} / \mathrm{well})$ were transferred to a polyvinylidene difluoride membrane following electrophoresis with $10 \%$ SDS-PAGE. the membrane was incubated for $2 \mathrm{~h}$ at room temperature in 5\% non-fat dry milk powder. The primary antibodies (rabbit anti-c-Met, ab51067, 1:200 dilution; rabbit anti-E-cadherin, ab76319, 1:200 dilution; both Abcam) were incubated at $4^{\circ} \mathrm{C}$ overnight, and the secondary antibody Horseradish peroxidase-labeled goat anti-rabbit secondary antibody (ab150077, 1:200, Abcam) was incubated at room temperature for $2 \mathrm{~h}$. An ECL chemiluminescence detection kit (Kangwei Century Biotechnology Co., Ltd., Beijing, China) was used to visualize the protein bands.

$R T-q P C R$. RNA was isolated from the cervical cancer tissues, adjacent normal tissues and cells in order to analyze the expression of miR-101 and CREB1 miRNA using qRT-PCR assays. The TRIzol extraction kit, cDNA amplification kit and miRNA extraction kit were purchased from Invitrogen (Thermo Fisher Scientific, Inc.), and the miRNA primer was synthesized by the Shanghai Biotechnology Company. The LightCycler 480 fluorescence qPCR instrument was purchased from Roche Applied Science (Penzberg, Germany). The U6 gene was used as the housekeeping gene in the RT-qPCR analysis, with the following primer sequences: F5'-GTTTTGTAGTTTTTG GAGTTAGTGTTGTGT-3' and R5'-CTCAACCTACAATCA AAAACAACACAAACA-3'.

Scratch test. A total of $48 \mathrm{~h}$ post-transfection, the cell surface was scratched with a sterile $10 \mu 1$ pipette tip, and the serum-free culture medium was replaced; this was recorded as timepoint $0 \mathrm{~h}$. A total of five fields were randomly selected and the migration of cells from the scratch to the center was observed using an inverted microscope at x400 magnification, and the distance between the two scratch lines was recorded at 0 and $12 \mathrm{~h}$. This experiment was repeated three times.

Transwell assay. HeLa cells were counted after $48 \mathrm{~h}$ for mRNA1 (or NC) transfection. Cell density was $\sim 5 \times 10^{4} / \mathrm{ml}$, using 24 orifice Transwell Chambers. A total of $200 \mu \mathrm{l}$ cell suspension along with $600 \mu \mathrm{l}$ cell culture were added into the upper chamber and the culture medium supplemented with $500 \mu 110 \%$ fetal bovine serum (FBS, Thermo Fisher Scientific, Inc.) was added to the lower chamber, respectively. At $24 \mathrm{~h}$, the Transwell chamber was removed and the cells in the upper chamber were removed with a cotton swab. The cells in the lower chamber were stained with $0.1 \%$ crystal violet for $20 \mathrm{~min}$ at $37^{\circ} \mathrm{C}$, which were observed and counted under the microscope. Repeat 3 times for each group.

Postoperative follow-up. A postoperative follow-up was conducted every 2 months among the 50 patients over a 2 -year period. The termination event to define survival analysis was mortality during follow-up, or reaching the maximum follow-up time. There were no lost cases during the 2-year follow-up and all patients were included in the survival analysis.

Statistical methods. Statistical analysis was performed using SPSS 17.0 (SPSS Inc, Chicago, IL, USA). Measurement data are presented as the mean \pm standard deviation. A two-tailed Student's t-test was performed to compare the sample means. The correlation between the test indexes and the clinicopathological features of the patients with cervical cancer was analyzed using the Pearson linear correlation test. The correlation between miRNA expression and clinicopathological features was analyzed using a $\chi^{2}$ test. Survival analysis was examined using the log-rank and Kaplan-Meier tests. $\mathrm{P}<0.05$ was considered to indicate a statistically significant difference.

\section{Results}

c-Met expression in cervical cancer tissues and the adjacent tissues. The proto-oncogene c-Met is a high-affinity receptor of hepatocyte growth factor (HGF). Its expression has been identified in normal and tumor cells, and its persistent activation may lead to tissue cell carcinogenesis or overactive tumor cell proliferation. In the immunohistochemical detection, it was observed that c-Met had markedly lower expression levels in the adjacent tissues compared with the cervical cancer tissues; tumor differentiation was accelerated with the increase in c-Met expression (Fig. 1), the elevated c-Met expression was able to promote cervical cancer progression. 


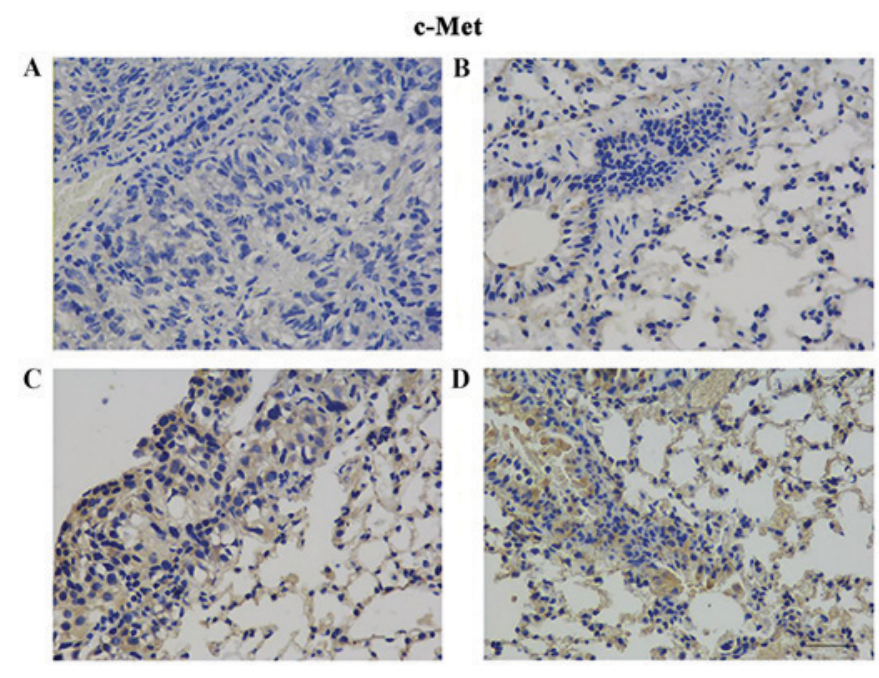

Figure 1. c-Met expression in cervical cancer tissues and adjacent tissues (A) normal (B) mildly (C) moderate (D) heavy, detected by immunohistochemistry (x200 magnification).

Correlation between $c$-Met, E-cadherin expression and the pathological features of cervical cancer. Pearson linear correlation analysis was conducted to evaluate the factors involved in cervical cancer prognosis. The results suggested that tumor size, FIGO staging and lymphatic metastasis were correlated with the prognosis of patients with cervical cancer $(\mathrm{P}<0.01$; Table I). A poor prognosis was defined as recurrence, metastasis or mortality.

E-cadherin is involved in cell adhesion and dissociation, and is closely associated with cervical cancer tumorigenesis and progression. Previous studies have reported that E-cadherin protein expression levels decrease with the progression of cervical cancer. By comparing the pathological features of cervical cancer, it was demonstrated that patients with higher c-Met expression levels tended to have lower E-cadherin expression levels; in the majority of cases, these patients had tumors $>4 \mathrm{~cm}$ with lymphatic metastasis, and their FIGO staging was above IIIb. By contrast, in patients with low c-Met expression levels, E-cadherin was highly expressed (Table II). These results demonstrated that E-cadherin expression in tumor tissues was negatively correlated with cervical cancer progression, while c-Met expression had a positive correlation with cervical cancer progression; c-Met may significantly inhibit and decrease E-cadherin expression, thus accelerating cervical cancer metastasis and progression.

c-Met, E-cadherin expression and cervical cancer prognosis. To further investigate the correlation between c-Met/E-cadherin expression levels and the overall survival of patients with cervical cancer, the 24-month follow-up records were analyzed using Kaplan-Meier and log-rank tests. The results demonstrated that patients with cervical cancer with high c-Met expression levels had a significantly lower survival rate compared with those with low c-Met expression levels ( $\mathrm{P}<0.05$; Fig. 2). It was additionally noted that patients with low E-cadherin expression levels in tumor tissues had a significantly lower survival rate compared with those with high E-cadherin expression levels ( $\mathrm{P}<0.05$; Fig. 3). It was concluded that high E-cadherin expression and low c-Met
Table I. Tumor size, FIGO staging and lymphatic metastasis were associated with the prognosis (recurrence, metastasis, mortality) of patients with cervical cancer.

\begin{tabular}{lcc}
$\begin{array}{l}\text { Clinicopathological } \\
\text { characteristics }\end{array}$ & $\chi^{2}$ & P-value \\
\hline $\begin{array}{l}\text { Tumor diameter }(\mathrm{cm}) \\
\geq 4\end{array}$ & 7.218 & $<0.01$ \\
$<4$ & & \\
FIGO stage & 10.833 & $<0.01$ \\
Ia IIb & & \\
IIIa & & \\
IIIb & & $<0.01$ \\
Lymph node metastases & 5.247 & \\
Yes & & \\
No & &
\end{tabular}

FIGO, Federation of Gynecology and Obstetrics.

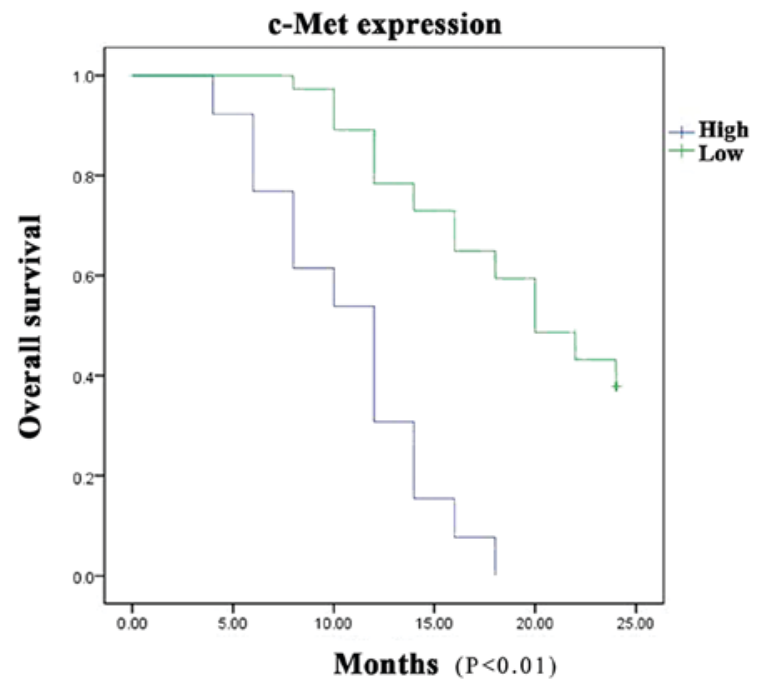

Figure 2. Kaplan-Meier plot comparing the overall survival rates between patients with high c-Met expression levels and low c-Met expression levels.

expression may increase the overall survival rate of patients with cervical cancer.

miRNA-1 expression in cervical tumor tissues. Multiple studies have demonstrated that miRNA-1 may inhibit c-Met expression by binding to the 3'UTR of c-Met. In the present study, using RT-qPCR to analyze the differential expression of miRNA-1 in tumor tissues and adjacent tissues, it was observed that miRNA expression was significantly decreased in tumor tissues compared with adjacent tissues (Fig. 4). By analyzing the pathological features of these patients with cervical cancer, it was observed that those with low miRNA-1 expression tended to have large tumor sizes $(>4 \mathrm{~cm})$, lymphatic metastasis and advanced FIGO staging (>IIIb); a larger number of patients with low miRNA-1 expression were at FIGO stage IIb-IIIa than at >IIIb; miRNA-1 expression in tumor tissues had a negative correlation with cervical cancer 
Table II. Association between c-Met/E-cadherin expression levels and pathological features of cervical cancer.

\begin{tabular}{|c|c|c|c|c|c|}
\hline \multirow[b]{2}{*}{ Variables } & \multirow[b]{2}{*}{ No. of cases } & \multicolumn{2}{|c|}{$\begin{array}{l}\text { Expression } \\
\text { levels of E-cadherin (n) }\end{array}$} & \multicolumn{2}{|c|}{$\begin{array}{c}\text { Expression } \\
\text { levels of c-Met (n) }\end{array}$} \\
\hline & & Low $=13$ & High=37 & Low $=34$ & High $=16$ \\
\hline \multicolumn{6}{|l|}{ Tumor size $(\mathrm{cm})$} \\
\hline$>4$ & 28 & 11 & 17 & 16 & 12 \\
\hline$<4$ & 22 & 2 & 20 & 18 & 4 \\
\hline \multicolumn{6}{|l|}{ FIGO stage } \\
\hline Ib-IIa & 29 & 2 & 27 & 26 & 3 \\
\hline IIb-IIIa & 13 & 3 & 10 & 8 & 5 \\
\hline IIIb and above & 8 & 8 & 0 & 0 & 8 \\
\hline \multicolumn{6}{|c|}{ Lymph node metastasis } \\
\hline Yes & 23 & 10 & 13 & 11 & 12 \\
\hline No & 27 & 3 & 24 & 23 & 4 \\
\hline
\end{tabular}

miRNA, microRNA; FIGO, Federation of Gynecology and Obstetrics.

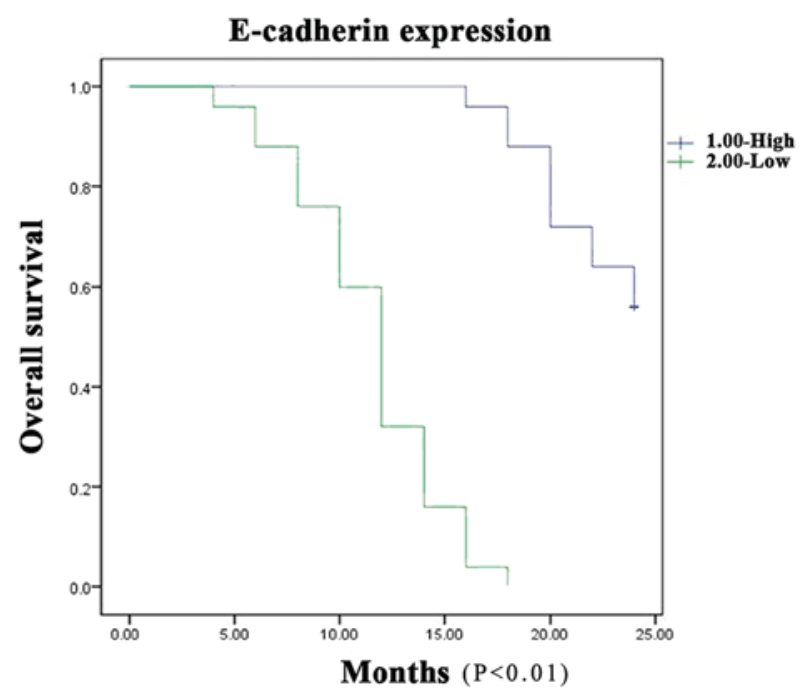

Figure 3. Kaplan-Meier plot comparing the overall survival rates between patients with high E-cadherin expression levels and low E-cadherin expression levels.

progression (Table III). The present study demonstrated that miRNA-1 may be involved in cervical cancer metastasis and progression by inhibiting c-Met expression.

miRNA-1 expression and cervical cancer prognosis. The analysis of the 24-month follow-up using the Kaplan-Meier and log-rank tests demonstrated that the patients with cervical cancer with low miRNA-1 expression in tumor tissues had a significantly lower survival rate compared with those with high miRNA-1 expression ( $\mathrm{P}<0.05$; Fig. 5), suggesting a close correlation between the miRNA-1 expression in tumor tissues and the survival of patients with cervical cancer.

miRNA-1 inhibits the proliferation and migration of cervical cancer cell lines by downregulating $c$-Met $m R N A$. Dual luciferase reporter analysis demonstrated that the fluorescence

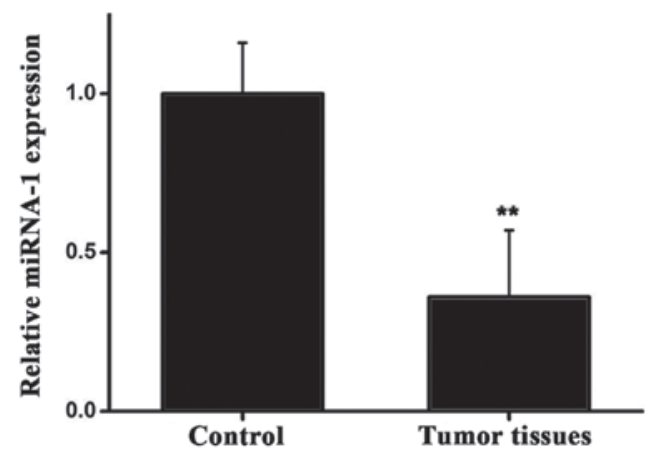

Figure 4. Relative miRNA-1 expression in cervical tumor tissues compared with the control. miRNA-1 expression levels were significantly decreased in tumor tissues compared with control. ${ }^{* *} \mathrm{P}<0.05$ vs. control. miRNA, microRNA.

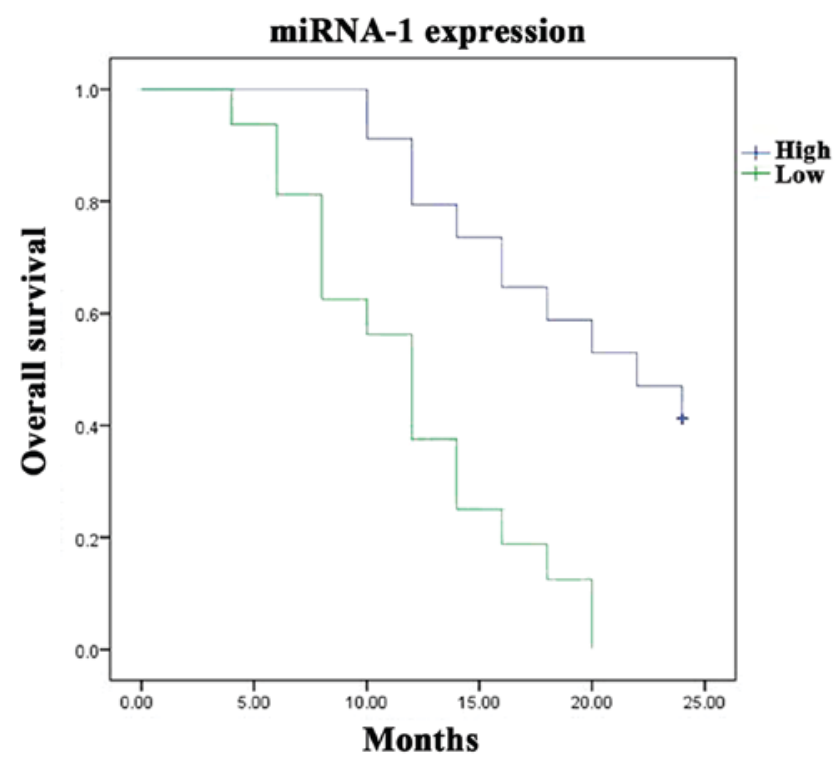

Figure 5. Kaplan-Meier plot comparing the overall survival rates between patients with high miRNA-1 expression levels and low miRNA-1 expression levels. miRNA, microRNA. 
Table III. Association between miRNA-1 expression levels and cervical cancer prognosis.

Expression levels of miRNA-1 (n)

Variables

No. of cases

Low $=25 \quad$ High $=25$

\begin{tabular}{lrrr}
\hline Tumor size $(\mathrm{cm})$ & & & \\
$>4$ & 28 & 23 & 5 \\
$<4$ & 22 & 2 & 20 \\
FIGO stage & & & \\
$\quad$ Ib-IIa & 29 & 5 & 24 \\
IIb-IIIa & 13 & 12 & 1 \\
IIIb and above & 8 & 8 & 0 \\
Lymph node metastasis & & & \\
$\quad$ Yes & 23 & 22 & 1 \\
No & 27 & 3 & 24 \\
\hline
\end{tabular}

miRNA, microRNA; FIGO, Federation of Gynecology and Obstetrics.

intensity of miRNA-1 did not significantly alter between the blank plasmid group and the control group ( $\mathrm{P}>0.05)$; however, in the c-Met 3 'UTR end mutation group, the fluorescence intensity of miRNA-1 was significantly decreased compared with that of the control group $(\mathrm{P}<0.01)$, suggesting that miRNA-1 may be able alter the fluorescence activity by combining with wild-type c-Met (Fig. 6A). In HeLa cells, overexpression of miRNA-1 markedly downregulated the mRNA and protein expression levels of c-Met (Fig. 6B and C). In addition, by the Tranwell assay, it was observed that the number of cells in the miRNA-1-treated group was decreased compared with the NC control group, miRNA-1 significantly inhibited cell migration (Fig. 6D). Furthermore, it was confirmed that miRNA-1-treated cells did not exhibit marked migration $12 \mathrm{~h}$ following the scratch test, suggesting that miRNA-1 may effectively inhibit the migratory ability of cervical cancer cells (Fig. 6E). Expression of miRNA-1 in cells was detected by RT-qPCR, suggesting that the transfection with miRNA-1 mimics in the present study was successful (Fig. 6F).

\section{Discussion}

In the present study, alterations in the expression levels of miRNA-1, c-Met and E-cadherin in tumor tissues and the adjacent tissues were analyzed. The results demonstrated that c-Met had a high expression levels in cervical cancer tissues, while miRNA-1 and E-cadherin had low expression levels in the cancerous tissues. Furthermore, the expression levels of miRNA-1, c-Met or E-cadherin were correlated with tumor size $(>4 \mathrm{~cm})$, FIGO stage ( $\geq \mathrm{III})$ and lymphatic metastasis. Thus, patients with cervical cancer exhibiting low c-Met expression and high E-cadherin and miRNA-1 expression, have higher survival rates. It was concluded that high E-cadherin and miRNA-1 expression levels in cervical cancer tissues may be associated with a favorable prognosis, while increased c-Met expression may be associated with poor prognosis.
By binding to specific complexes that are able to induce RNA silencing, miRNAs are able to form miRNA interference vectors, and recognize target gene mRNAs via complementary base pairing. When mismatches between the miRNA interference vector and the target gene mRNA occur, the mRNA translation is suppressed. When there is a complete match, the target gene mRNA is specifically degraded (14). miRNA-1 is expressed abnormally in a variety of tumor cells and is involved in tumor proliferation, invasion, migration and apoptosis. Previous studies have demonstrated that miRNA-1 is downregulated in nasopharyngeal cancer (15), prostate cancer (16), colon cancer (17), lung cancer (18) and laryngeal cancer (19), and functions as a tumor suppressor gene. However, it is upregulated in stomach cancer and functions as a cancer-promoting gene (20). The present study demonstrated that the expression level of miRNA-1 in cervical cancer tissues was decreased compared with the adjacent tissues, which indicated that miRNA-1 was downregulated in cervical cancer and had a positive correlation with large tumor size $(>4 \mathrm{~cm})$, advanced FIGO staging (a larger number of patients with low miRNA-1 expression were at FIGO stage IIb-IIIa) and lymphatic metastasis, suggesting that miRNA-1 functions as a tumor suppressor gene in cervical cancer. It was demonstrated that miRNA-1 serves the role of a tumor suppressor gene in cervical cancer and serves a regulatory role in the migration, invasion and proliferation of cervical cancer.

miRNA-1 has multiple target genes, including histone deacetylase-4, cyclin D2 and LIM and SH3 domain protein 1, which are involved in cell migration, proliferation, differentiation and apoptosis. c-Met is also a target gene of miRNA-1 and is involved in cell proliferation and migration. c-Met is the tyrosine kinase transmembrane receptor of HGF. It is encoded by proto-oncogene Met and activated by a single ligand. The HGF/c-Met signaling pathway serves a key role in physiological processes, including embryonic development and tissue damage repair (21). Abnormal HGF/c-Met signal transduction is associated with malignant tumorigenesis, particularly tumor cell invasion and metastasis. c-Met, primarily expressed in epithelial cells, is able to promote embryonic development, damage repair and tissue regeneration under normal circumstances (22). The high c-Met expression in malignant tumor cells consistently activates the HGF/c-Met signaling pathway, forming an unregulated abnormal HGF/c-Met autocrine feedback loop, thereby inducing and activating adhesion factors, degrading the extracellular matrix, accelerating neovascularization, and promoting tumor cell proliferation, differentiation, invasion and metastasis $(23,24)$. The present study identified that c-Met expression levels in patients with cervical intraepithelial neoplasia (CIN) grade 3 were higher compared with those with CIN1 and CIN2; patients who were positive for HPV had higher c-Met expression levels compared with patients who were negative for HPV. In addition, there was a negative correlation between c-Met expression and disease prognosis. Therefore, c-Met may be involved in the development and progression of cervical cancer. Overexpression of c-Met is associated with the transformation of normal cells and the development of tumors (25). In the present study, it was determined that c-Met expression levels were increased in tumor tissues compared with adjacent tissues; in addition, expression levels were elevated with the progression of 


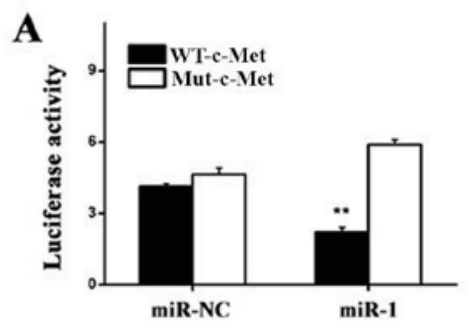

D
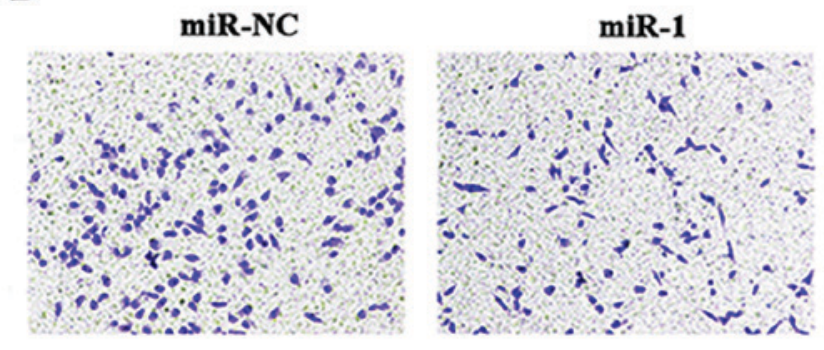

\section{F}

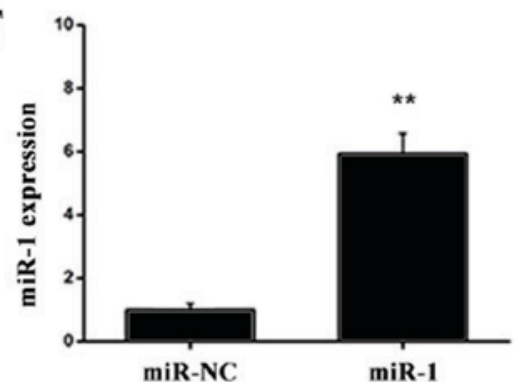

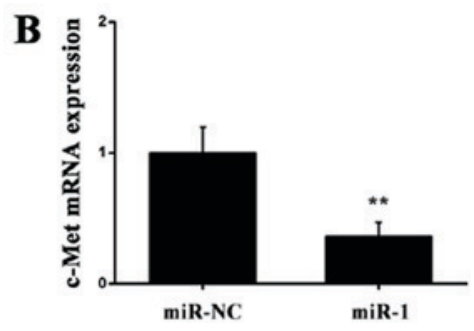

C

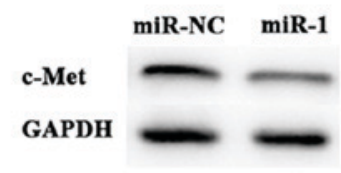

$\mathbf{E}$
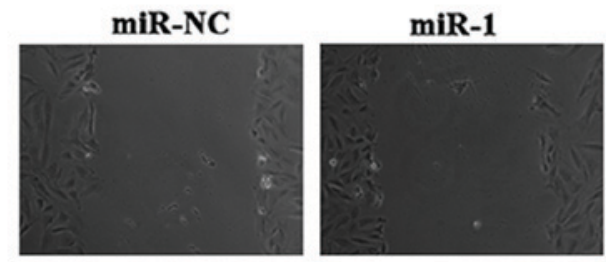

$12 \mathrm{~h}$
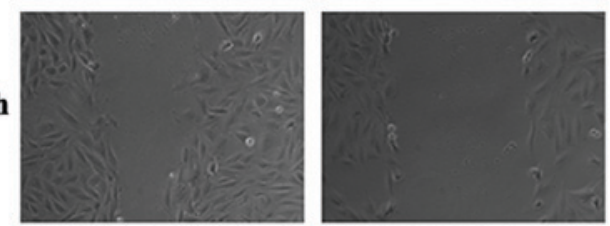

Figure 6. miRNA-1 inhibits the proliferation and migration of cervical cancer cell lines by downregulating c-Met mRNA expression levels. (A) The dual luciferase reporter gene assay. ${ }^{* *} \mathrm{P}<0.01$ vs. Mut-c-Met. (B) The c-Met mRNA expression level in miRNA-1-overexpressing HeLa cells compared with NC. ${ }^{* *} \mathrm{P}<0.01$ vs. NC. (C) Western blot displaying the c-Met protein expression level in miRNA-1-overexpressing HeLa cells compared with NC. (D) The Transwell staining of HeLa cells treated with miRNA-1 compared with NC (x100 magnification). (E) Results from the scratch test at 0 and 12 h. (F) miRNA-1 expression was upregulated in the transfected cells, as demonstrated via reverse transcription-quantitative polymerase chain reaction. ${ }^{* *} \mathrm{P}<0.01 \mathrm{vs}$. NC. miRNA, microRNA; NC, negative control; WT, wild-type; Mut, mutant.

cervical cancer, and positively correlated with large tumor size $(>4 \mathrm{~cm})$, advanced FIGO staging ( $\geq$ IIIb) and lymphatic metastasis $(\mathrm{P}<0.01)$, demonstrating that $\mathrm{c}-$ Met may be involved in cervical cancer invasion and metastasis. To investigate whether miRNA-1 targets c-Met, miRNA-1 was synthesized and transfected into HeLa cells. The expression of c-Met was detected by RT-qPCR and immunoblotting, and it was observed that miRNA-1 may significantly inhibit the expression of c-Met. By the scratch test, it was demonstrated that miRNA-1 may effectively inhibit the proliferation and migration of cervical cancer cells. Furthermore, it was demonstrated that miRNA-1 was able to bind to the 3 'UTR end of c-Met in cervical cancer cells through the dual luciferase reporter assay, thus inhibiting the expression of c-Met.

The tumorigenesis, progression, invasion and metastasis of cervical cancer are closely associated with EMT, in which the epithelial cells lose their cell polarity and cell-cell adhesion, and gain migratory properties to become mesenchymal cells. E-cadherin is a marker of epithelial cells; its decreased expression levels may weaken the adhesion between tumor cells, making them more migratory and invasive, and promoting tumor metastasis from the primary lesion to the blood vessels and other tissues. Reduced E-cadherin expression levels are correlated with the severity of the epithelial phenotype deletion, and the advancement of EMT $(26,27)$. It has been reported that c-Met regulates the EMT process of tumor cells, and that the upregulation of c-Met expression in cancer tissues promotes EMT progression. By comparing and analyzing cervical cancer tissues and normal adjacent tissues, the present study revealed that in cervical cancer tissues, c-Met had elevated expression levels, while E-cadherin had decreased expression levels, which is in accordance with the conclusions in the literature $(28,29)$; elevated c-Met expression may induce EMT and promote cervical cancer progression.

Recent studies have demonstrated that miRNA-1 may inhibit c-Met expression by binding to the 3' UTR of c-Met (30-32). Therefore, whether miRNA-1 has the potential to arrest the EMT of cancerous tissues by inhibiting c-Met expression, and whether miRNA-1 expression alterations in cervical cancer tissues may impact patient survival, requires further study. By analyzing the follow-up data, the present study observed that high miRNA-1 and E-cadherin expression levels, in addition to low c-Met expression levels, were correlated with high survival rates in patients with cervical cancer.

In conclusion, miRNA-1 has an important regulatory role with respect to c-Met and serves an important role in the development and prognosis of cervical cancer. The present study confirmed that miRNA-1 was downregulated in cervical cancer and reversed the inhibition of c-Met expression, resulting in a significant upregulation of c-Met expression. 
Elevated c-Met expression levels promote EMT, migration and infiltration, and reduce the survival rate of patients with cancer. Therefore, miRNA-1 may be a promising novel therapy for the treatment of cervical cancer.

\section{Acknowledgements}

Not applicable.

\section{Funding}

No funding was received.

\section{Availability of data and materials}

The datasets used and/or analyzed during the current study are available from the corresponding author on reasonable request.

\section{Authors' contributions}

YC designed the study, performed experiments, analyzed the data and wrote the manuscript. JP and MY performed the experiments, analyzed the data and drafted the manuscript. YC designed and supervised the study, and edited the manuscript.

\section{Ethics approval and consent to participate}

Written informed consent was obtained from all patients and the experiment was approved by the ethics committee of The People's Hospital of Inner Mongolia Autonomous Region (Zhaowuda Road, Inner Mongolia). All the procedures were performed in accordance with national (D.L.n.26, March 4th, 2014) and international laws and policies (directive 2010/63/EU), and was approved by the Ethics Committee, The People's Hospital of Inner Mongolia Autonomous Region.

\section{Patient consent for publication}

Not applicable.

\section{Competing interests}

The authors declare that they have no competing interests.

\section{References}

1. Everatt R and Intaite B: Trends in cervical cancer mortality rates in Lithuania, 1987-2016. Cancer Epidemiol 57: 85-89, 2018.

2. Haleshappa RA, Thanky AH, Kuntegowdanahalli L, Kanakasetty GB, Dasappa L and Jacob L: Epidemiology and outcomes of nasopharyngeal carcinoma: Experience from a regional cancer center in Southern Indi. South Asian J Cancer 6: 122-124, 2017.

3. Wang H, Zhao Y, Chen M and Cui J: Identification of novel long non-coding and circular RNAs in human papillomavirus-mediated cervical cancer. Front Microbiol 8: 1720, 2017.

4. Holubekova V, Mendelova A, Jasek K, Mersakova S, Zubor P and Lasabova Z: Epigenetic regulation by DNA methylation and miRNA molecules in cancer. Future Oncol 13: 2217-2222, 2017.

5. Blissenbach B, Nakas CT, Krönke M, Geiser T, Merz TM and Pichler Hefti J: Hypoxia-induced changes in plasma microRNAs correlate with pulmonary artery pressure at high altitude. Am J Physiol Lung Cell Mol Physiol 314: L157-L164, 2018.
6. Li LJ, Zhao W, Tao SS, Leng RX, Fan YG, Pan HF and Ye DQ: Competitive endogenous RNA network: Potential implication for systemic lupus erythematosus. Expert Opin Ther Targets 21: 639-648, 2017.

7. Zheng Y, Yin L, Chen H, Yang S, Pan C, Lu S, Miao M and Jiao B: miR-376a suppresses proliferation and induces apoptosis in hepatocellular carcinoma. FEBS Lett 586: 2396-2403, 2012.

8. Krol J, Loedige I and Filipowicz W: The widespread regulation of microRNA biogenesis, function and decay. Nat Rev Genet 11: 597-610, 2010.

9. Ferraz C, Lorenz S, Wojtas B, Bornstein SR, Paschke R and Eszlinger M: Inverse correlation of miRNA and cell cycle-associated genes suggests influence of miRNA on benign thyroid nodule tumorigenesis. J Clin Endocrinol Metab 98: E8-E16, 2013.

10. Yip L, Kelly L, Shuai Y, Armstrong MJ, Nikiforov YE, Carty SE and Nikiforova MN: MicroRNA signature distinguishes the degree of aggressiveness of papillary thyroid carcinoma. Ann Surg Oncol 18: 2035-2041, 2011.

11. Shen X, Pan B, Zhou H, Liu L, Lv T, Zhu J, Huang X and Tian J: Differentiation of mesenchymal stem cells into cardiomyocytes is regulated by miRNA-1-2 via WNT signaling pathway. J Biomed Sci 24: 29, 2017.

12. Su DN, Wu SP, Chen HT and He JH: HOTAIR, a long non-coding RNA driver of malignancy whose expression is activated by FOXC1, negatively regulates miRNA-1 in hepatocellular carcinoma. Oncol Lett 12: 4061-4067, 2016.

13. Laughlin-Tommaso SK, Hesley GK, Hopkins MR, Brandt KR, Zhu Y and Stewart EA: Clinical limitations of the international federation of gynecology and obstetrics (FIGO) classification of uterine fibroids. Int J Gynaecol Obstet 139: 143-148, 2017.

14. Carthew RW and Sontheimer EJ: Origins and mechanisms of miRNAs and siRNAs. Cell 136: 642-655, 2009.

15. Wu CD, Kuo YS, Wu HC and Lin CT: MicroRNA-1 induces apoptosis by targeting prothymosin alpha in nasopharyngeal carcinoma cells. J Biomed Sci 18: 80, 2011.

16. Kojima S, Chiyomaru T, Kawakami K, Yoshino H, Enokida H, Nohata N, Fuse M, Ichikawa T, Naya Y, Nakagawa M and Seki N: Tumour suppressors miR-1 and miR-133a target the oncogenic function of purine nucleoside phosphorylase (PNP) in prostate cancer. Br J Cancer 106: 405-413, 2012.

17. Oberg AL, French AJ, Sarver AL, Subramanian S, Morlan BW, Riska SM, Borralho PM, Cunningham JM, Boardman LA, Wang L, et al: miRNA expression in colon polyps provides evidence for a multihit model of colon cancer. PLoS One 6: e20465, 2011.

18. Melkamu T, Zhang X, Tan J, Zeng Y and Kassie F: Alteration of microRNA expression in vinyl carbamate-induced mouse lung tumors and modulation by the chemopreventive agent indole-3-carbinol. Carcinogenesis 31: 252-258, 2010.

19. Wang P, Fu T, Wang $X$ and Zhu W: Primary, study of miRNA expression patterns in laryngeal carcinoma by microarray. Lin Chung Er Bi Yan Hou Tou Jing Wai Ke Za Zhi 24: 535-538, 2010 (In Chinese).

20. Liu R, Zhang C, Hu Z, Li G, Wang C, Yang C, Huang D, Chen X, Zhang $\mathrm{H}$, Zhuang R, et al: A five-microRNA signature identified from genome-wide serum microRNA expression profiling serves as a fingerprint for gastric cancer diagnosis. Eur J Cancer 47: 784-791, 2011.

21. Duan Z, Choy E, Nielsen GP, Rosenberg A, Iafrate J, Yang C, Schwab J, Mankin H, Xavier R and Hornicek FJ: Differential expression of microRNA (miRNA) in chordoma reveals a role for miRNA-1 in Met expression. J Orthop Res 28: 746-752, 2010.

22. Morgillo F, Amendola G, Della Corte CM, Giacomelli C, Botta L, Di Maro S, Messere A, Ciaramella V, Taliani S, Marinelli L, et al: Dual MET and SMO negative modulators overcome resistance to EGFR inhibitors in human nonsmall cell lung cancer. J Med Chem 60: 7447-7458, 2017.

23. Hsieh YS, Liao CH, Chen WS, Pai JT and Weng MS: Shikonin inhibited migration and invasion of human lung cancer cells via suppression of c-met-mediated epithelial-to-mesenchymal transition. J Cell Biochem 118: 4639-4651, 2017.

24. Tomihara H, Yamada D, Eguchi H, Iwagami Y, Noda T, Asaoka T, Wada H, Kawamoto K, Gotoh K, Takeda Y, et al: MicroRNA-181b-5p, ETS1, and the c-Met pathway exacerbate the prognosis of pancreatic ductal adenocarcinoma after radiation therapy. Cancer Sci 108: 398-407, 2017.

25. Li X, Sun X, Wu J and Li Z: MicroRNA-613 suppresses proliferation, migration and invasion of osteosarcoma by targeting c-MET. Am J Cancer Res 6: 2869-2879, 2016. 
26. Chen HA, Kuo TC, Tseng CF, Ma JT, Yang ST, Yen CJ, Yang CY, Sung SY and Su JL: Angiopoietin-like protein 1 antagonizes MET receptor activity to repress sorafenib resistance and cancer stemness in hepatocellular carcinoma. Hepatology 64: 1637-1651, 2016.

27. Liu WT, Jing YY, Yu GF, Chen H, Han ZP, Yu DD, Fan QM, Ye F, Li R, Gao L, et al: Hepatic stellate cell promoted hepatoma cell invasion via the HGF/c-Met signaling pathway regulated by p53. Cell Cycle 15: 886-894, 2016.

28. Maione F,Capano S, ReganoD,Zentilin L, Giacca M, Casanovas O, Bussolino F, Serini G and Giraudo E: Semaphorin 3A overcomes cancer hypoxia and metastatic dissemination induced by antiangiogenic treatment in mice. J Clin Invest 122: 1832-1848, 2012

29. Xu X, Zhu Y, Liang Z, Li S, Xu X, Wang X, Wu J, Hu Z, Meng S, Liu B, et al: c-Met and CREB1 are involved in miR-433-mediated inhibition of the epithelial-mesenchymal transition in bladder cancer by regulating Akt/GSK-3 $\beta /$ Snail signaling. Cell Death Dis 7: e2088, 2016.
30. Yan D, Dong Xda E, Chen X, Wang L, Lu C, Wang J, Qu J and Tu L: MicroRNA-1/206 targets c-Met and inhibits rhabdomyosarcoma development. J Biol Chem 284: 29596-29604, 2009.

31. Duan Z, Shen J, Yang X, Yang P, Osaka E, Choy E, Cote G, Harmon D, Zhang Y, Nielsen GP, et al: Prognostic significance of miRNA-1 (miR-1) expression in patients with chordoma. J Orthop Res 32: 695-701, 2014.

32. Duan Z, Choy E, Nielsen GP, Rosenberg A, Iafrate J, Yang C, Schwab J, Mankin H, Xavier R and Hornicek FJ: Differential expression of microRNA (miRNA) in chordoma reveals a role for miRNA-1 in Met expression. J Orthop Res 28: 746-752, 2010.

(7)(9) This work is licensed under a Creative Commons Attribution-NonCommercial-NoDerivatives 4.0 International (CC BY-NC-ND 4.0) License. 